\title{
Medical considerations in dental treatment of patients with Williams-Beuren syndrome: report of four clinical cases
}

\author{
- Natália Silva Andrade Discipline of Oral Pathology, Department of Stomatology, School of Dentistry, University of São \\ Paulo, São Paulo, SP, Brazil • Cíntia Santos Discipline of Oral Pathology, Department of Stomatology, School of Dentistry, \\ University of São Paulo, São Paulo, SP, Brazil • Talita Castro Discipline of Oral Pathology, Department of Stomatology, School \\ of Dentistry, University of São Paulo, São Paulo, SP, Brazil • Marina Gallottini Discipline of Oral Pathology, Department of \\ Stomatology, School of Dentistry, University of São Paulo, São Paulo, SP, Brazil
}

ABSTRACT | Williams-Beuren syndrome (WBS) is a rare genetic disorder characterized by peculiar facies, eyes, dental, cardiovascular, renal, and skeletal abnormalities, mental retardation, friendly and loquacious personality, and occasionally hypercalcemia in infancy. The orofacial aspects and especially the dental management of these patients have received little attention in the literature. The aim of this manuscript is to describe four cases of patients with WBS attended at Special Care Dentistry Center, School of Dentistry, University of São Paulo, with emphasis on the oral findings and systemic conditions of dental interest. The clinical management of patients with WBS is discussed. We conclude that congenital heart defects and behavioral changes are the aspects that most interfere on dental treatment.

DESCRIPTORS | Williams Syndrome; Dental Treatment; Heart Diseases.

RESUMO | Considerações médicas no tratamento odontológico de pacientes com síndrome de Williams-Beuren: relato de quatro casos clínicos • Síndrome de Williams-Beuren (SWB) é uma doença genética rara, caracterizada por anomalias peculiares em face e olho, odontológicas, cardiovasculares, renais e esqueléticas, retardo mental, personalidade amigável e comunicativa e, ocasionalmente, hipercalcemia na infância. Os aspectos orofaciais e, especialmente, o manejo odontológico desses pacientes têm recebido pouca atenção na literatura. O objetivo deste artigo é descrever quatro casos de pacientes com SWB atendidos no Centro de Atendimento a Pacientes Especiais da Faculdade de Odontologia da Universidade de São Paulo, com ênfase nos achados bucais e condições médicas de interesse para odontologia. O manejo clínico de pacientes com SWB é discutido. Conclui-se que os defeitos cardíacos congênitos e mudanças de comportamento são os aspectos que mais interferem no tratamento odontológico de paciente com SWB.

DESCRITORES | Síndrome de Williams; Tratamento Odontológico; Cardiopatias

AUTOR CORRESPONDENTE | Marina Gallottini Department of Stomatology, School of Dentistry, University of São
Paulo • Av. Professor Lineu Prestes, 2227, São Paulo, SP, Brazil $\mathbf{0 5 5 0 8 - 9 0 0 ~ E ~ m a i l ~}$ mhcgmaga@usp.br

- Received Fev 10, 2015 - Accepted Apr 6, 2015

- Dol http://dx.doi.org/10.11606/issn.2357-8041.clrd.2016.118463 


\section{INTRODUCTION}

The Williams-Beuren syndrome (WBS) is a rare genetic disorder that occurs sporadically, with an incidence of 1:20,000 to 1:50,000 live births. It was firstly described in 1961 by the cardiologist John Williams, and in 1962 Beuren expanded the syndrome's features. It affects both sexes equally and seems to occur in all ethnic groups around the world. Individuals with this syndrome have peculiar facies, dental development disorders, eyes, heart, kidney, and skeletal abnormalities, mental retardation, friendly and loquacious personality, and occasionally hypercalcemia during infancy., ${ }^{1,2}$

Individuals with WBS present hemizygous microdeletion or deletion of contiguous gene in $7 q 11.23$ region that alter the function of several genes, including those responsible for the production of elastin. ${ }^{3}$ The diagnosis of the syndrome is clinical, but the confirmation occurs through identification of the gene deletion by fluorescent in situ hybridization (FISH) test. ${ }^{4}$

Elastin is a structural protein of the extracellular matrix which composes $90 \%$ of elastic fibers and it is responsible for reestablishment of various tissues after distention. Elastin is organized into elastic fibers in the walls of arteries, skin, lungs, gut, cartilage, ligaments and joints as well as alterations in its synthesis can lead to cardiovascular problems, ligamentous laxity, and joint contractures. ${ }^{5}$

Cardiovascular changes are very important due to their high frequency and clinical impact. The most common finding is the supravalvular aortic stenosis (SVAS), followed by pulmonary artery stenosis and mitral valve prolapsed. ${ }^{2}$ Hypercalcemia is the presence of high levels of calcium in blood, and only $15 \%$ of individuals with WBS present this idiopathic condition that usually regresses until 4 years old. ${ }^{6}$

The typical facial appearance of individuals with WBS is described by several authors as "elfin face" and is characterized by periorbital fat accumulation, low nasal bridge, prominent cheeks, long nasal filter, thick lips, bitemporal depression, small and upturned nose, small chin, stellate iris pattern (observed mainly in individuals with light eyes), strabismus, malocclusion, and disorders of dental development. ${ }^{2}$

Among the dental development disorders, the most mentioned ones in literature are microdontia, hypodontia, small roots, fused tooth, twinned tooth, taurodontism, enamel hypoplasia, and presence of generalized diastemas.7 Occlusal changes have also been described, including predominantly Angle class III malocclusion.

Considering that many dental development disorders may require careful treatment plan, it is important for the dentist to recognize and to search for these changes in people with WBS. Thus, the dentist can anticipate the dental needs and know the systemic implications to provide an efficient and safe dental care to the patient.

\section{CASE REPORTS}

CASE 1 - Patient P.L.G.O., male, 8 years old, diagnosed with WBS at 7 years old through the FISH test, went to the Special Care Dentistry Center (SCDC), School of Dentistry, University of São Paulo for dental treatment. He had thick lips, prominent cheeks, depressed nasal bridge, small nose, and accumulation of periorbital fat (Figure 1A). Medical history revealed SVAS, pulmonary stenosis, heart murmur, arterial and pulmonary hypertension, renal failure, severe mental retardation, skeletal growth delay, hyperactivity, hyperacusis, pulmonary fibrosis, and gastroesophageal reflux. During the first two years of life, the patient had suffered a stroke and three acute myocardial infarctions. Since then, the patient has been treated with two types of diuretics, association of three antihypertensive drugs, anticonvulsant, anti-thrombotic, and gastric protector. He is in the waiting list for a heart transplant. 

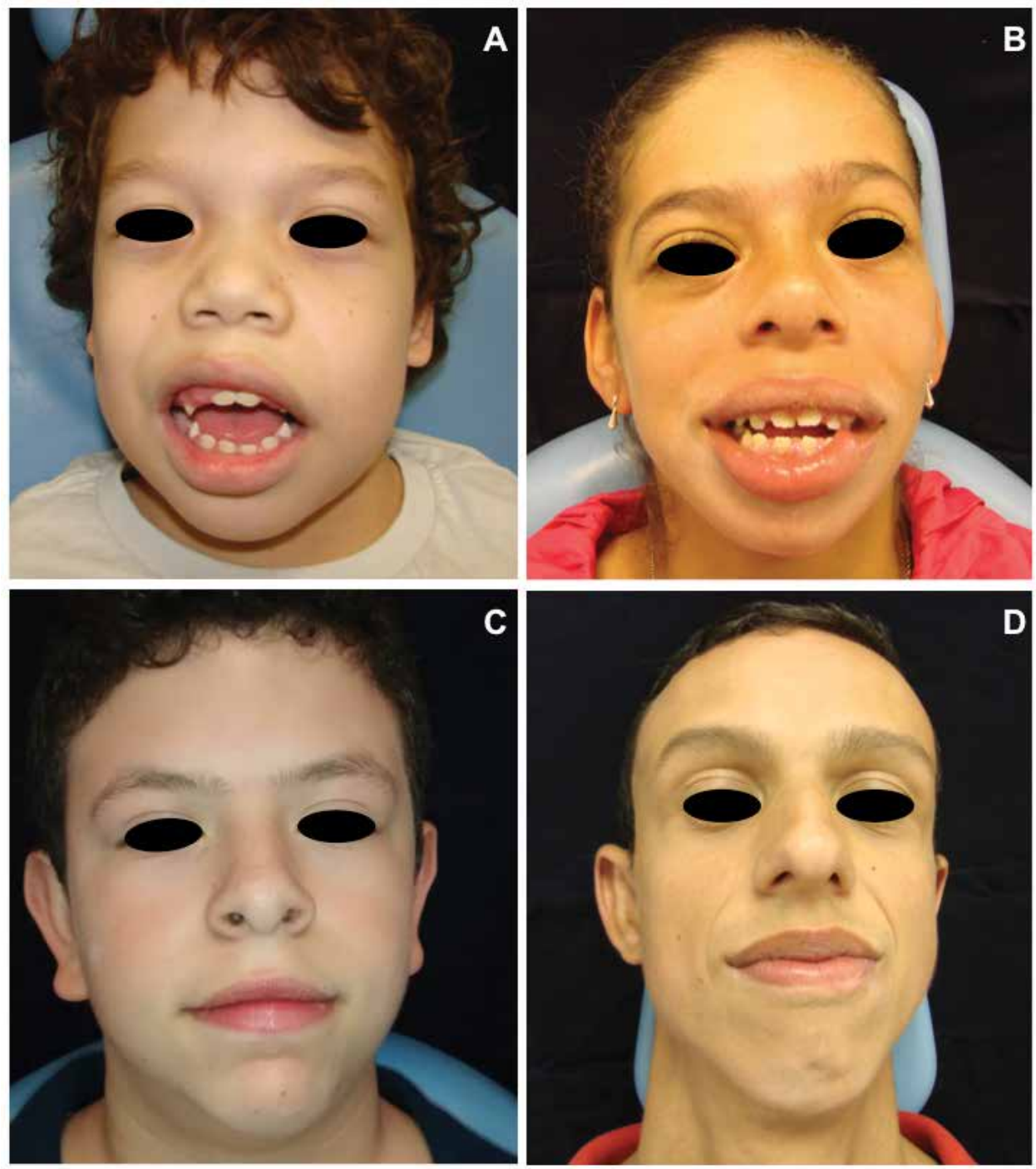

FIGURA 1 | Orofacial and dental characteristics of patients with Williams-Beuren syndrome. A) Case 1 showing thick lips, prominent cheeks, depressed nasal bridge, small nose, and accumulation of periorbital fat. Generalized diastemas and gingival hyperplasia can also be seen. B) Case 2 showing thick lips, prominent cheeks, depressed nasal bridge, small nose, small chin, generalized diastemas, and malocclusion. C) Case 3 showing thick lips, prominent cheeks, and long nasal filter. D) Case 4 showing features like thick lips, long nasal filter, and small chin.

Clinical examination revealed mixed dentition, some deciduous teeth with prolonged retention, generalized diastemas, three teeth with caries, thick biofilm, spontaneous gingival bleeding, and gingival hyperplasia. The boy breathed through the mouth, remained with his tongue interposed between the front teeth, and had the habit of grinding the teeth at night. His bite was open and classified as Angle class III malocclusion. Due to lack of cooperation and to the large amount of required dental procedures, it was decided with the cardiologist to perform the treatment under general anesthesia. The treatment plan included restoration of decayed teeth, tooth extractions, periodontal scaling, and topical application of fluoride varnish. The mother was instructed on the importance of proper oral hygiene and the maintenance of good oral health, especially facing the possibility of heart transplantation. 
CASE 2 - Patient B.E.M.S., female adolescent, 15 years old, positive for FISH test at the age of four, sought the SCDC for routine dental treatment. She had typical facies, showing thick lips, prominent cheeks, depressed nasal bridge, small nose, small chin, and starry iris (Figure 1B). Medical history revealed that the SVAS was surgically corrected in early childhood, but the heart murmur persisted, as well as high blood pressure, kidney failure, severe mental retardation, growth retardation, hyperactivity, and hyperacusis. She has been regularly taking two antihypertensive medications, two types of diuretics, vasodilators, intestinal regulator, and gastric protector.

The patient had permanent dentition with generalized diastemas, three teeth with caries, generalized gingival bleeding, and drug-induced gingival enlargement grade 2. She was breathing through the mouth and interposing the tongue between the anterior teeth. She showed anterior crossbite, open bite, and malocclusion type II division 1, according to the Angle classification. Dental treatment was carried out in dental clinic without sedation although she did not wholly cooperate with the oral management. Sometimes certain degree of passive physical restraint was needed. We noticed the sensitivity of patient to the sounds of sucking and high-revving engine. Supra and sub gingival scraping and restoration of teeth with dental caries were performed. We have decided not to perform gingivoplasty due to poor cooperation of the patient, and the switch to hypotensive drug was not considered by cardiologists. We followed the recommendations of the American Heart Association ${ }^{8}$ and since her congenital cardiopathy had been corrected surgically we did not perform prophylactic antibiotics before sub gingival scraping. Returns for preventive therapy were recommended every 6 months.

CASE 3 - Patient P.V.C., male, 11 years old, diagnosed with WBS at 9 years old by FISH test, presented to the SCDC complaining about caries and gingival bleeding. He showed thick lips, prominent cheeks, and long nasal filter (Figure 1C), mild mental retardation, hypothyroidism, and hyperacusis. He did not exhibit any congenital heart disease. He was using thyroid hormone for treating hypothyroidism since 10 years old. He breathed through the mouth, reported sleep snoring and bruxism. The occlusion examination revealed crossed and open bite, class II Angle malocclusion, and atypical swallowing.

He presented mixed dentition with prolonged retention of primary teeth, generalized diastemas, several teeth with dental caries, gingival bleeding on probing, hypertrophic labial frenulum, and enamel hypoplasia in several teeth. Panoramic radiograph confirms hypodontia of maxillary lateral incisors teeth. The patient cooperated entirely with treatment, which included restorations with composite resin, scraping, and periodontal polishing. Returns for preventive therapy were recommended every 6 months and orthodontic treatment was nominated.

CASE 4 - Patient F.S.S., male, 22 years old, tested positive for FISH at 10 years old, presented for dental treatment, exhibiting typical WBS features like thick lips, long nasal filter, and small chin (Figure 1D). He presented mild mental retardation, supravalvar aortic stenosis, surgically corrected in childhood, and persistent murmur heart.

His teeth were free of caries, but gengivitis was present since he showed gingival bleeding on probing. His orthodontic treatment was carried out at SCDC for 10 years. He had deep bite and hypodontia of the upper right second premolar. The supragingival scraping and extraction of all third molars, which were misplaced, were carried out without any resistance of the patient. Prophylactic antibiotics were not prescribed since he had his congenital cardiopathy surgically corrected during his childhood. 


\section{DISCUSSION}

We presented four clinical cases of three children and a young man with WBS with oral changes and different systemic disorders linked to the syndrome, which illustrate the wide clinical spectrum of this syndrome.

The main systemic disorders that interfere directly in the dental clinical management of patients with WBS are heart disease and behavior alterations. Cardiovascular abnormalities caused by deficiency of elastin occur in $80 \%$ of WBS individuals, being the SVAS the most frequent heart defect. Cardiovascular diseases are significant causes of morbidity and mortality in WBS with risk of sudden death. The literature shows that when the correction is possible, the immediate surgical results are low mortality and good results with stable pressure gradient and without restenosis. ${ }^{1}$

Among our cases, three had a history of significant heart diseases, which had been surgically corrected in the patients 2 and 4 . The patient 1 was awaiting heart transplantation, and his severe and unstable cardiovascular condition contraindicated dental treatment at that time. Since the removal of oral infection foci is important to the patient, the cardiologist was trying to compensate him before heart transplantation.

In Case 2, neither heart disease nor hypertension limited dental intervention, since the patient was stable. She was taking amlodipine (calcium channel blocker) $5 \mathrm{mg}$ two times a day, causing gingival overgrowth. Proper conduct for patients with hypertension is to measure the blood pressure (BP) before starting all dental visits. She was stable and the hypertension was under control. For this reason, the cardiologist decided to maintain the current medication even with it causing gingival overgrowth. The gingivoplasty was not performed due to poor cooperation of the patient. The stress caused by this surgery, as well as the slight discomfort after surgery, could contribute to increase BP of the patient. Considering that dental treatment should not interfere on the patient's hemodynamics, we avoided dental procedures that generate rapid changes in $\mathrm{BP}$, heart rate, and myocardial oxygen demand. Therefore the dentist should minimize this stress by scheduling the patient in calm times, performing short visits, properly controlling the operative pain, and avoiding elective procedures.

Hypertension is described in $40-70 \%$ of children with WBS and is associated with aortic coarctation, nephrocalcinosis, nephropathy or renal failure, and diffuse arterial disease with few cases refractory to medication. It can be manifested later at school age and should be important to perform hypertension research in patients with WBS. ${ }^{9}$

Another systemic change that interfered with dental treatment was hyperacusis, which affects the patient's behavior during the consultation. Approximately $94 \%$ of subjects with $\mathrm{WBS}^{4}$ have heightened sensitivity to sounds. The implication in dental treatment may be directly related to the sounds of high revving engine and sucking, which can be very uncomfortable for people with WBS.

In the cases 1, 2 and 3, the individuals exhibited caries. The literature provides conflicting data on the incidence of dental caries in people with WBS. Mozkovits et al. ${ }^{2}$ reports that there is no difference in the decay rate in the general population comparing to WBS individuals. Axelsson et al. 7 commented that dental caries in WBS may be the result of an association between enamel hypoplasia, hypomineralization and poor oral hygiene. Our patients had poor oral hygiene and gingivitis. The malocclusion, mental retardation, and poor control of plaque put them in a high risk category for caries.

The microdeletion of chromosome 7, which determines the establishment of WBS, may include some genes directly involved in odontogenesis as the genes clustered family TFII-I (Gtf2i, Gtf2ird1 and Gtf2ird2) and its absence of expression seems 
to be related with some tooth development disturbances such as changes in shape, number, hypodontia and enamel hypoplasia. ${ }^{10}$ Development disorders of teeth observed in the cases described herein included hypodontia, generalized diastemas, prolonged retention of deciduous teeth, teeth with altered morphology and enamel hypoplasia. Early diagnosis and treatment of these disorders involve better oral health conditions in adulthood.

The hypodontia can be managed with prostheses or implants and the tooth shape changes can be corrected with direct (composite resin) or indirect (porcelain) restorations. Orthopedic and orthodontic treatment will correct the occlusal alterations, and should be performed when WBS individuals cooperate, as seen in Cases 3 and 4.

Although the behavioral aspects of individuals with WBS is predominantly hyperactive and most of them show significant mental retardation, exacerbated sympathy and talkativeness may give the false impression to the dentist that the management will be easy and the cooperation of the patient is guaranteed.

Moskovits et al. ${ }^{2}$ point out that dentists should consider the hyperactive behavior of patients with WBS as an obstacle and use sedation orally or inhaled, as well as general anesthesia to reduce anxiety and overcome lack of cooperation of young patients. However, treatments under general anesthesia may have serious consequences in patients with WBS because of their heart problems. The findings of Olsen et al. ${ }^{11}$ suggested high rates of cardiac complications, so they recommend a serious analysis of the benefit-risk for general anesthesia, as there are reports of cases of sudden death related to the procedure. Our patient 1 waits for future release of the cardiologist for general anesthesia running for dental treatment.

\section{CONCLUSION}

Before starting the dental treatment, the dentist should be aware about the cardiac condition of the patient with WBS, and identify their behavior in the doctor's office. The disturbance of dental development, especially hypodontia, should be considered in the dental treatment plan.

\section{REFERENCES}

1. Sugayama SMM, Moisés RL, Wagënfur J, Ikari NM, Abe KT, Leone C, et al. Síndrome de Williams-Beuren. Anomalias cardiovasculares em 20 pacientes diagnosticados pela hibridização in situ por fluorescência. Arq Bras Cardiol. 2003 Nov;81(5):462-7. doi: 10.1590/Soo66-782X2003001300003.

2. Moskovitz M, Brener D, Faibis S, Peretz B. Medical considerations in dental treatment of children with Williams syndrome. Oral Surg Oral Med Oral Pathol Oral Radiol Endod. 2005 May;99(5):573-8o. doi: 10.1016/j.tripleo.2004.03.019.

3. Elçioglu N, Mackie-Ogilvie C, Daker M, Berry AC. FISH analysis in patients with clinical diagnosis of Williams Syndrome. Acta Paediatr. 1998 Jan;87(1):48-53. doi: 10.1111/ j.1651-2227.1998.tbo1384.x.

4. Honjo RS, Dutra RL, Furusawa EA, Zanardo EA, Costa LSA, Kulikowski LD, et al. Williams-Beuren Syndrome: a Clinical Study of 55 Brazilian Patients and the Diagnostic Use of MLPA. Biomed Res Int. 2015;2015:568047. Epub 2015 oct 8. doi: 10.1155/2015/568047.

5. Morris CA. Genetic aspects of supravalvular aortic stenosis. Curr Opin Cardiol. 1998 May;13(3):214-9.

6. Lameris AL, Geesim CL, Hoenderop JG, Schreuder MF. Importance of dietary calcium and vitamin $\mathrm{D}$ in the treatment of hypercalcaemia in Wlliams Beuren syndrome. J Pediatr Endocrinol Metab. 2014 Jul;27(7-8):757-61. doi: 10.1515/ jpem-2013-0229.

7. Axelsson S, Bjornland T, Kjaer I, Heiberg A, Storhaug K. Dental characteristics in Williams syndrome: a clinical and radiographic evaluation. Acta Odontol Scand. 2003 Jun;61(3):12936. doi: 10.1080/000163503110001451.

8. Wilson W, Taubert KA, Gewitz M, Lockhart PB, Baddour LM, Levison M, et al. Prevention of infective endocarditis: guidelines from the American Heart Association: a guideline from the American Heart Association Rheumatic Fever, Endocarditis, and Kawasaki Disease Committee, Council on Cardiovascular Disease in the Young, and the Council on Clinical 
Cardiology, Council on Cardiovascular Surgery and Anesthesia, and the Quality of Care and Outcomes Research Interdisciplinary Working Group. Circulation. 2007;116(15):1736-54. doi: 10.1161/CIRCULATIONAHA.106.183095.

9. Sylos C, Pereira AC, Azeka E, Miura N, Mesquita SMF, Ebaid M. Hipertensão arterial em criança portadora de síndrome de Williams-Beuren. Arq Bras Cardiol. 2002 Ago;79(2):173-6. doi: 10.1590/Soo66-782X2002001100009.
10. Ohazama A, Sharpe PT. TFII-I gene family during tooth development: candidate genes for tooth anomalies in Williams syndrome. Dev Dyn. 2007 Oct;236(10):2884-8. doi: 10.1002/ dvdy.21311.

11. Olsen M, Fahy CJ, Costi DA, Kelly AJ, Burgoyne LL. Anaesthesia-related haemodynamic complications in Williams syndrome patients: a review of one institution's experience. Anaesth Intensive Care. 2014 Sep;42(5):619-24. 